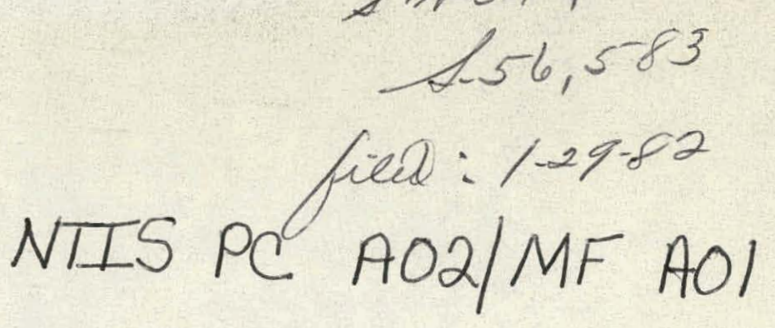$$
\text { PATENTS-US - A } 343803
$$

PATENTS-US--A343803

DE83 002387

\title{
METHOD FOR FORMING MICROSPHERES FOR \\ ENCAPSULATION OF NUCLEAR WASTE
}

Inventors: Peter Angelini

109 Berwick Drive

Oak Ridge, Tennessee 37830

U.S. Citizen

0
1
1
00
I
1
1
1
0
+1
1
1
3

Anthony J. Caputo

8044 Gleason Road, Apt\#C-15

Knoxville, Tennessee 37919

U.S. Citizen

Richard E. Hutchens

3813 Debonair Drive

Knoxville, Tennessee

37912

U.S. Citizen

Walter J. Lackey

103 Newcrest Lane

Oak Ridge, Tennessee 37830

U.S. Citizen

David P. Stinton

10929 Sallings Road

Knoxville, Tennessee 37922

U.S. Citizen 


\section{DISCLAIMER}

This report was prepared as an account of work sponsored by an agency of the United States Government. Neither the United States Government nor any agency Thereof, nor any of their employees, makes any warranty, express or implied, or assumes any legal liability or responsibility for the accuracy, completeness, or usefulness of any information, apparatus, product, or process disclosed, or represents that its use would not infringe privately owned rights. Reference herein to any specific commercial product, process, or service by trade name, trademark, manufacturer, or otherwise does not necessarily constitute or imply its endorsement, recommendation, or favoring by the United States Government or any agency thereof. The views and opinions of authors expressed herein do not necessarily state or reflect those of the United States Government or any agency thereof. 


\section{DISCLAIMER}

Portions of this document may be illegible in electronic image products. Images are produced from the best available original document. 


\section{METHON FOR FORMING MICROSPHERES FOR \\ ENCAPSULATION OF NUCLEAR WASTE}

\section{Background of the Invention}

This invention was made under a contract with the United States

5 Department of Energy and relates to a process for making particles in which nuclear waste is immobilized.

To facilitate its handling and storage, nuclear waste has been incorporated in small spherical particles (referred to hereinafter as microspheres) which are made by various well-known sol-gel processes.

10. In the usual manufacturing procedure such microspheres are gelled while dropping through a liquid and then washed with an aqueous solution before being dried and hardened by calcination, the washing step being required to remove from the microspheres materials such as nitrates and organic compounds that cause them to develop defects (e.g., cracks and

15 blisters that reduce structural stability), or even to disintegrate, during calcination. However, a soluble nuclear waste such as cesium is dissolved from microspheres by the conventional wash step, thus defeating the purpose of encapsulating such waste in the microspheres and producing a radioactive liquid that is difficult to dispose of.

\section{Surmary of the Invention}

The object of this invention is to provide a process for forming nuclear waste immobilizing microspheres which are free of defects even though they are not washed before calcination as required heretofore. 
Because the microspheres are not washed in the process of the. invention; they retain even soluble species such as cesium.

This object is achieved by drying and calcining unwashed microspheres of the described type under conditions such that volatile

5 material is removed therefrom at a substantially linear mass loss rate throughout the period of drying and calcination. The temperature or humidity that is required to remove volatile components from microspheres at a uniform rate can be ascertained by providing a furnace with (1) a balance on which a sample of microspheres is held, and

10 (2) means associated with the balance for controlling temperature or humidity in the furnace in a manner which maintains the necessary uniform rate of removal of the volatile components. More particularly, temperature in the furnace is decreased when the balance senses a nonuniform rise in the mass loss rate of volatile material from a sample

15 of microspheres, and furnace temperature is increased when the balance senses a non-uniform drop in mass loss rate. In a furnace operated with humidity control of mass loss rate, humidity is increased when the balance senses a non-uniform rise in mass loss rate and decreased when the balance senses a non-uniform drop in mass loss rate. The

20 temperature-time schedule or humidity-time schedule recorded when a substantially linear mass loss rate has been achieved in the balanceequipped furnace is then programmed into the operation of large scale furnaces used for drying and calcining microspheres.

\section{Description of the Drawings}

25 Fig. 1 is a graph depicting mass loss rate of unwashed gel-derived microspheres calcined in accordance with the process of the invention. 
Fig. 2 is a graph depicting mass loss rate of unwashed gel-derived microspheres calcined in a furnace wherein temperature is increased in a conventional manner.

\section{Detailed Description of the Invention}

Microspheres containing nuclear waste can be made by the internal gelation process wherein droplets of a chilled feed broth containing the waste, matrix components, urea and hexamethylenetetramine (referred to hereinafter as HMTA) are fed to a heated immiscible gelation liquid, the droplets being gelled as they sink in the liquid by ammonia pro-

10 duced from the decomposition of the HMTA.

Waste sludges are partially dissolved in nitric acid and a solution of matrix elements is added to this mixture to provide the feed solution. Most feed solutions of this type contain some suspended solids but these can be tolerated by the gelation system. Urea is dissolved

15 in the feed solution to complex metal ions and prevent premature gelation with HMTA. The adjusted feed is cooled to $0^{\circ} \mathrm{C}$ or a slightly lower temperature and then mixed with an HMTA solution precooled to $0^{\circ} \mathrm{C}$. The chilled feed broth is fed through a vibrating nozzle into a column of immiscible gelation liquid maintained at a temperature of $55^{\circ} \mathrm{C}$, which

20 gelation liquid may consist of various hydrocarbons such as a mixture containing 45 vol.\% 2-ethylhexanol and 55 vol.\% trichloroethylene. In one solution tested in the process of the invention a small concentration ( 0.05 vol.\%) of a surfactant (Span-80) was dissolved in the gelation liquid to prevent coalescence of microspheres and attachment of 25 microspheres to the column holding the gelation liquid. Ammonium 
hydroxide is released by decomposition of HMTA, which is activated by the elevated temperature of the gelation liquid and accelerated by the acidity of the feed solution, causing droplets of the feed broth to gel within 5 to 15 seconds as they fall through the liquid. At this point,

5 the collected microspheres are ready for further processing in accordance with the invention, and the aging and washing steps used in conventional microsphere production processes are not required or performed.

Simulated nuclear waste compositions of two different types were

10 prepared and tested in the process of the invention, namely, a composition representative of the type of waste associated with defense systems and a composition representative of the type of waste associated with the production of power for commercial purposes. The composition of the simulated defense waste used as feed material for product micro-

15 spheres are shown in the following table, wherein concentrations listed under "Product Microspheres" represent the weight percent of the named materials in microspheres obtained by means of the disclosed process with $\mathrm{ZrO}_{2}$ as a matrix material.

Table I

Defense-Type NucTear Waste

Component

Dry Metal Oxide Basis

$\mathrm{Fe}_{2} \mathrm{O}_{3}$

25
$\mathrm{Al}_{2} \mathrm{O}_{3}$

$\mathrm{MnO}_{2}$

$\mathrm{U}_{3} \mathrm{O}_{8}$

$\mathrm{CaO}$

$\mathrm{NiO}$
Concentration (Weight \%)

Waste Matrix Product Microspheres

49.9

9.8

13.7

4.5

3.7

6.2
44.9

8.8

12.4

4.1

3.3

5.6 
Table I

Defense-Type Nuclear Waste

Continued

5

Dry Metal Oxide Basis

$\mathrm{SiO}_{2}$

$\mathrm{Na}_{2} \mathrm{O}$

10

$\mathrm{Na}_{2} \mathrm{SO}_{4}$

$\mathrm{Ce}_{2} \mathrm{O}_{3}$

$\mathrm{Nd}_{2} \mathrm{~N}_{3}$

$\mathrm{SrO}$

$\mathrm{ZrO}_{2}$
Concentration (Weight \%)

Waste

1.2

7.0

1.3

1.1

1.1

0.5
1.1

6.3

1.2

0.9

0.9

0.5

100

The composition of simulated commercial waste tested in the process of the invention is shown in the following table.

Table II

Commercial-Type Nuclear Waste

20

Component

Dry Metal 0xide Basis

$\operatorname{SrO}$

$\mathrm{Nd}_{2} \mathrm{O}_{3}$

25

30

$$
\mathrm{Mo}_{2} \mathrm{O}_{3}
$$

$\mathrm{Ru}_{2} \mathrm{O}_{3}$

$\mathrm{Cs}_{2} \mathrm{n}_{2}$

$\mathrm{TiO}_{2}$

$\mathrm{Al}_{2} \mathrm{O}_{3}$

$\mathrm{ZrO} 2$

$\mathrm{BaO}$

$\mathrm{CaO}$
Concentration (Weight \%)

Waste Matrix Product Microspheres

13.1

15.1

15.4

15.0

41.3

0.26

0.30

0.31

0.30

0.82

60.7

11.1

10.0

4.2

14.0
59.5

10.8

9.8

4.2

13.7

Gelation conditions used in the preparation of the simulated wastes of Tables I and II are presented in the following table. 


\section{Table II I}

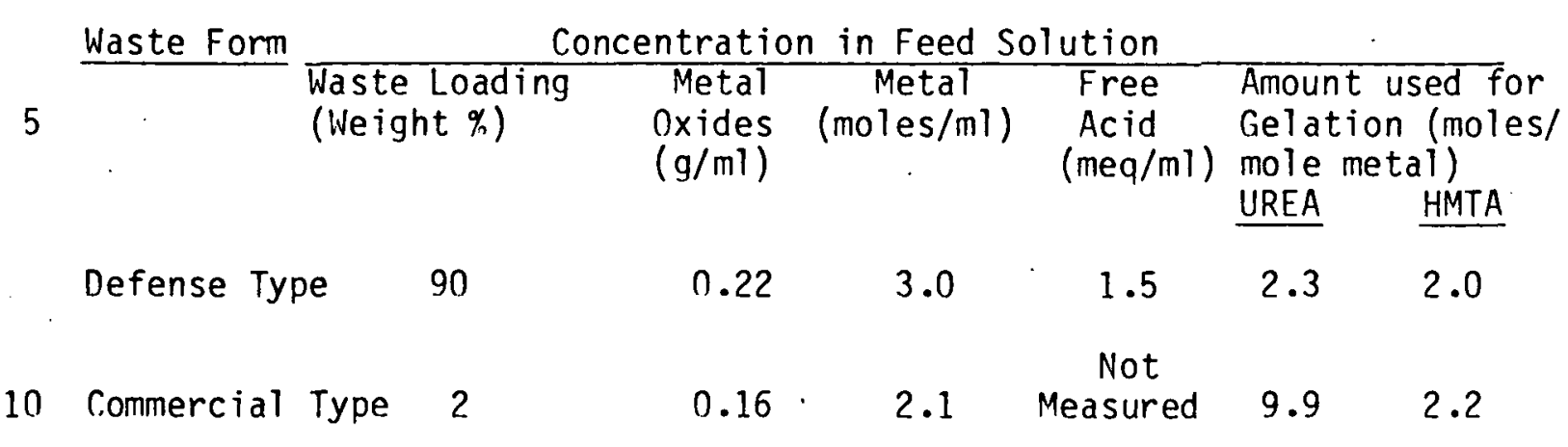

Nuclear fuel particles were also prepared and tested. Uranium oxide spheres were prepared by the internal gelation process in a similar manner as previously described. The uranium feed solution was

15 at a concentration near $0.4 \mathrm{~g} \mathrm{U}_{3} \mathrm{O}_{8} / \mathrm{ml}$. The final solution was partially denitrated (acid deficient). The urea and HMTA requirements were somewhat less than the values for nuclear waste materials. Unwashed spheres were tested. The second type of nuclear fuel particle which was tested was $U C_{x} 0_{y}$. In this case, the spheres were washed and

20 dried and were produced by the external gelation process. The objective in this case was to prevent cracking due to chemical reactions occurring in narrow temperature regions during the calcination and sintering process.

\section{Test Example I}

25 Unwashed gel-derived microspheres containing the simulated defense-type nuclear waste composition tabulated in Table I were successfully dried and calcined by means of the following equipment: 
a nuPont Instruments 951 Thermogravimetric Analyzer; (2) a DuPont Instruments 990 Thermal Analyzer; and (3) an Analog Series Macsym 2 Computer. The system was operated in the following manner. A sample of gelled microspheres was placed in the thermogravimetric analyzer,

5 and an output signal representing the derivative of the mass of the sample with respect to time was continuously monitored as a function of time by the computer. The computer compared the actual mass loss derivative with a prescribed value and a difference was calculated. A signal proportional to this difference was used by the computer to

10 control the heater power supply of the thermogravimetric analyzer. This feedback control loop. resulted in a temperature schedule in the furnace that assured drying and calcination of the microspheres in the desired uniform microsphere mass loss rate shown in Fig. 1. The left ordinate in this graph represents the mass loss rate expressed as per15 centage of the initial mass of the sample, the right ordinate represents the temperature of the sample during the drying and calcining period, and the abscissa represents time. The sample consisted of $19.43 \mathrm{mg}$ of unwashed gel spheres. It will be noted that the mass loss rate of the sample was substantially linear throughout the drying and 20 calcining period, this linearity being achieved by controlling temperature in the furnace as shown on the graph. The volatile material removed from the microspheres included water, HMTA, urea, ammonia, and nitrate and chloride compounds. The microspheres obtained by the described process conditions were of good quality. Fig. 2 illustrates data obtained when a $12.71 \mathrm{mg}$ sample of the same type of gel spheres containing simulated defense waste was dried 
and calcined by the conventional method. In this test, furnace temperature was increased at a rate of $5^{\circ} \mathrm{C} /$ minute throughout the drying and calcining period. Included in Fig. 2 is a curve illustrating the derivative of mass with respect to time during the conventional furnace

5 heating test. This mass derivative curve shows the extremely rapid decomposition of the test sample which occurred at a temperature of about $200^{\circ} \mathrm{C}$ and which completely ruined the microspheres.

\section{Test Example II}

Unwashed gel-derived microspheres containing the simulated commer-

10 cial nuclear waste composition tabulated in Table II were successfully processed using the equipment described in Test Example I. The resulting microspheres had good structural properties and were completely suitable for further processing. However, to process a larger sample of the commercial waste microspheres $(30 \mathrm{gm})$, the temperature versus time

15 schedule followed during the use of the aforesaid equipment and drying and calcining procedure was recorded and an Astro Model No. 725-S furnace was then programmed by means of a computer to follow the same temperature versus time schedule during the drying and calcining of the larger sample in the furnace. The microspheres thus obtained again

20 possessed excellent characteristics which made them well-suited for further processing.

\section{Test Example III}

The removal of volatile material from gel-derived microspheres at a substantially linear mass loss rate in accordance with the process of

25 the invention provides the additional advantage of shortening the 
drying time of washed gel-derived microspheres. In a test using a BMA Envrionmental Chamber with a volume of $8 \mathrm{ft}^{3}$, an Arbor balance in the aforesaid chamber for holding a sample and detecting its mass loss, and an Analog nevices Macsym 2 Computer for controlling temperature in the

5. chamber to provide a linear mass loss rate, $400 \mathrm{gm}$ of the previously described simulated commercial nuclear waste microspheres were properly dried and calcined in 2 hours whereas the normal drying and calcining procedure requires 24 hours.

\section{Test Example IV}

10 The equipment described in Test Example III was used to control the drying and calcination of the previously described simulated commerical nuclear waste microspheres, with the modification that humidity in the BMA Environmental Chamber was used to control the rate of removal of volatile components from the microspheres. That is, the mass

15 loss rate of the microspheres was maintained substantially linear over the drying and calcining period by an arrangement which automatically increased humidity in the chamber when the mass loss rate tended to vary from the desired linearity by increasing in a non-uniform manner, and vice versa. The sample of microspheres in this test weighed

20 approxiamtely 300 grams, and the resulting product had good structural characteristics.

\section{Test Example V}

Unwashed gel-derived microspheres of uranium oxide were successfully processed in accordance with the principles of the invention using

25 the equipment described in Test Example I. The resulting microspheres 
had good structural properties. The sample included $27.15 \mathrm{mg}$ of unwashed gel spheres. An argon flow of $50 \mathrm{cc} / \mathrm{min}$ was passed over the spheres and the temperature was permitted to go to $600^{\circ} \mathrm{C}$ maximum. The spheres lost $57 \%$ of their mass in a 170 minute run. A linear mass loss 5 rate of $0.3 \% /$ min was maintained during the run. Another experiment using $24.02 \mathrm{mg}$ sample of the same gel-derived microspheres was processed in a conventional manner with an increase in oven temperature of $2^{\circ} \mathrm{C}$ per minute up to $650^{\circ} \mathrm{C}$ and produced cracked, unusable spheres.

\section{Test Example VI} Washed and predried samples of $U C_{x} O_{y}(x+y$ being equal to 2$)$ nuclear fuel were processed in accordance with the principles of the invention. A $51.64 \mathrm{mg}$ sample was run in an argon atmosphere. The spheres had good mechanical and physical properties with very few particles broken. The sample was dried and calcined so that it exhibited

15 nearly linear weight loss during a run time of approximately 2 hours. 


\section{METHOD FOR FORMING MICROSPHERES FOR \\ ENCAPSULATION OF MUCLEAR WASTE \\ Abstract of the Disclosure}

Microspheres for nuclear waste storage are formed by gelling

5 droplets containing the waste in a gelation fluid, transferring the gelled droplets to a furnace without the washing step previously used, and heating the unwashed gelled droplets in the furnace under temperature or humidity conditions that result in a substantially linear rate of removal of volatile components therefrom. 


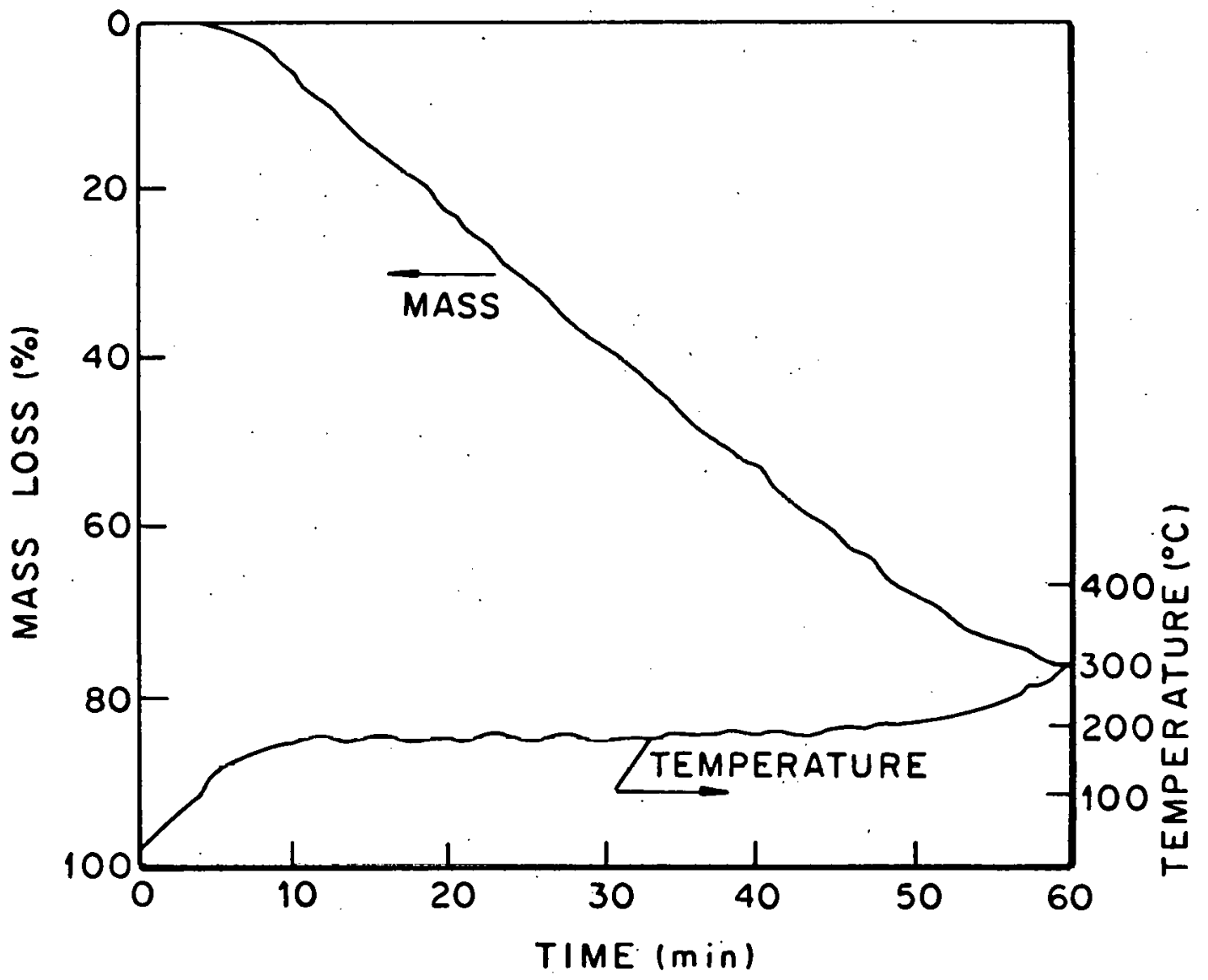

Fig. 1 


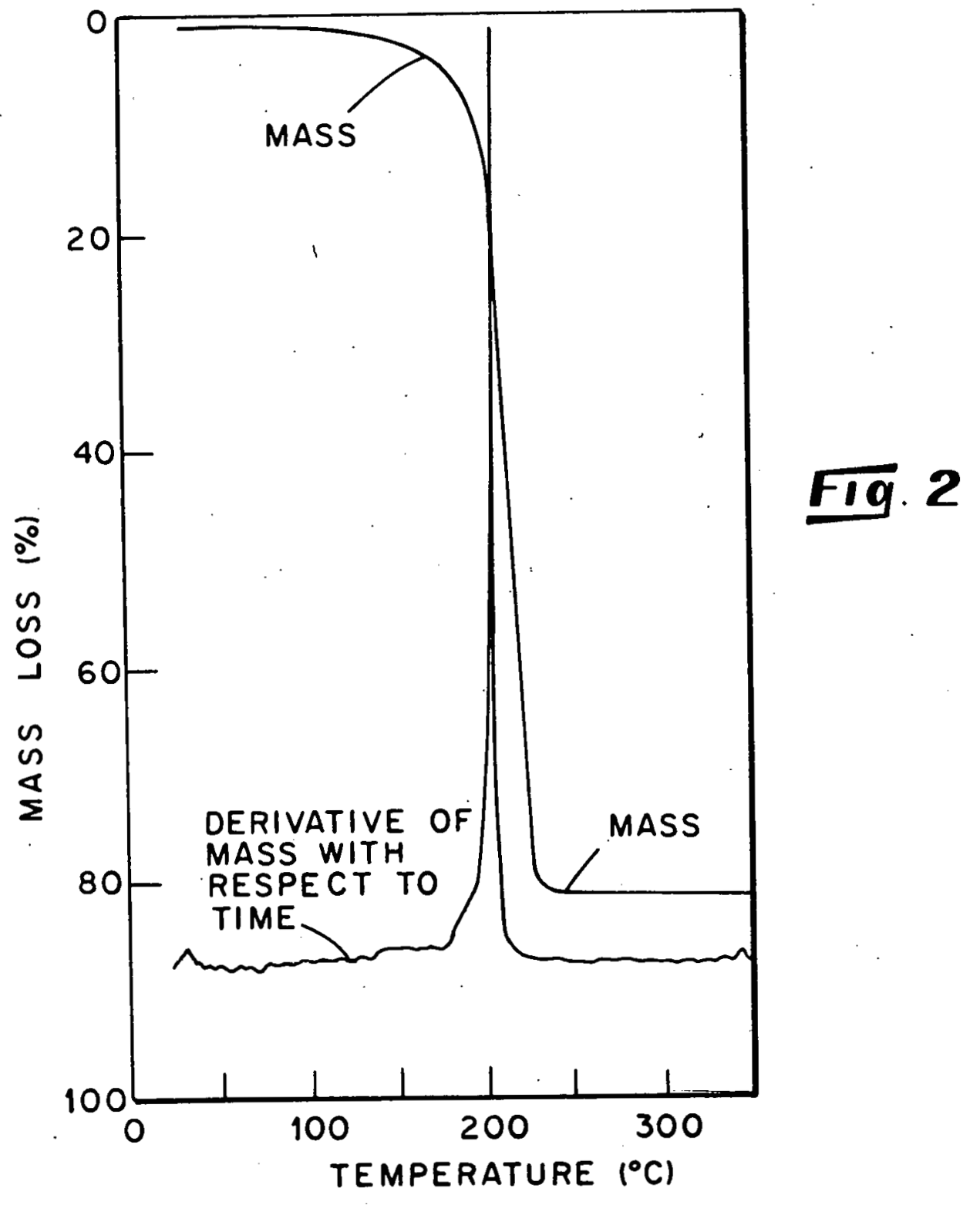

